\begin{tabular}{|c|l|}
\hline Title & Surfactant-assisted synthesis of Sn nanoparticles via solution plasma technique \\
\hline Author(s) & Saito, Genki; Z Zhu, Chunyu; A kiyama, Tomohiro \\
\hline Citation & $\begin{array}{l}\text { Advanced Powder Technology, 25(2), 728 732 } \\
\text { https://doi.org/L0.1016/.apt.2013.11.001 }\end{array}$ \\
\hline Issue Date & 201403 \\
\hline Doc URL & http://hdl.handle.net/2115/57597 \\
\hline Type & article(author version) \\
\hline File Information & GENKI_Sn_battery_ver13FIG_3.pdf \\
\hline
\end{tabular}

Instructions for use 


\title{
Surfactant-assisted synthesis of Sn nanoparticles via solution plasma technique
}

\author{
Genki Saito ${ }^{\mathrm{a}}$, Chunyu Zhu ${ }^{\mathrm{a}}$, and Tomohiro Akiyama, \\ ${ }^{\text {a }}$ Center for Advanced Research of Energy and Materials, Hokkaido University,
}

Sapporo 060-8628, Japan

* Corresponding Author: E-mail: takiyama@eng.hokudai.ac.jp

Tel.: +81-11-706-6842 Fax.: +81-11-726-0731 


\begin{abstract}
We have adopted a solution plasma synthesis for preparing Sn nanoparticles ( $\mathrm{Sn}-\mathrm{NPs}$ ) directly from metallic Sn electrode. The Sn-NPs were synthesized in the presence of the surfactant, cetyltrimethylammonium bromide (CTAB), and the effect of the concentration of CTAB on the Sn-NPs was investigated. Without CTAB addition, SnO plates were precipitated. Sn-NPs with less than $200 \mathrm{~nm}$ were synthesized at a high concentration of $200 \times 10^{-6} \mathrm{~g} \cdot \mathrm{ml}^{-1}$ of CTAB. Electrochemical properties of SnO plates and Sn-NPs were analyzed for use as an anode material in Li-ion batteries. A composite of Sn-NPs and graphite enhanced the cyclic stability owing to the buffer space provided by the graphite for volume expansion. In the case of the $30 \mathrm{wt} \%$ loaded Sn-NPs, the capacity was measured to be $414 \mathrm{mAh} \cdot \mathrm{g}^{-1}$ after 20 cycles.
\end{abstract}




\section{Keywords}

Tin, Sn-nanoparticles/graphite composite, nanoparticle, solution plasma synthesis,

Li-ion battery, anode 


\section{Introduction}

During the last two decades, lithium ion (Li-ion) batteries have been widely used as energy storage devices for applications, such as portable electronic devices and electric vehicles. Current Li-ion batteries, with graphite and other carbonaceous materials as standard anode materials, have a maximum theoretical capacity of $372 \mathrm{mAh} \cdot \mathrm{g}^{-1}$. Although this capacity is not considered very low, new anode materials with higher capacities are required to produce lightweight batteries with high energy density. Recently, Sn anodes have attracted much attention because of their high theoretical capacity of $992 \mathrm{mAh} \cdot \mathrm{g}^{-1}$ to form a $\mathrm{Li}_{4.4} \mathrm{Sn}_{\text {alloy }}{ }^{1-3}$. However, during lithium insertion/extraction process, a large volume change ( $>300 \%)$ inevitably occurs. This leads to pulverization of the tin anode and loss of electric contact to current collector, resulting in poor cycling performance ${ }^{4,5}$. Consequently, several strategies, including the formation of tin-based alloy ${ }^{6,7}$, reducing the particle size to nanoscale, and dispersion of nano-Sn in conductive carbon matrix to form tin/carbon composite ${ }^{8-18}$, have been proposed to mitigate this volume change issue.

In this study, we have adopted a novel solution plasma technique for preparing Sn-NPs. In this solution plasma technique ${ }^{19-20}$, an electrode was used as the raw material for the preparation of nanocrystals. Various nanoparticles such as $\mathrm{Ni}^{19,20}, \mathrm{Au}^{20,21}, \mathrm{ZnO}^{22}$ 
have been synthesized via solution plasma. In general, the solution plasma technique offers many advantages, such as (1) simple experimental setup, (2) no requirement for gas supply, (3) higher productivity than conventional solution processes, and (4) applicability to mass production. Recently, our research group demonstrated the synthesis of SnO plates by solution plasma technique, reported by us elsewhere ${ }^{23}$. In that study, we observed that the addition of surfactant CTAB to the electrolyte resulted in the formation of small amount of Sn phase. However, to the best of our knowledge, synthesis of Sn-NPs during solution plasma has not yet been reported. Therefore, in this study, we have analyzed the effect of CTAB concentration on the synthesis of Sn-NPs via solution plasma method. Further, we have evaluated the electrochemical performance as anode material for Li-ion battery.

\section{Experimental}

\subsection{Synthesis and characterization of Sn nanoparticles}

The setup consisted of two electrodes in a glass cell, the details of which has been reported previously ${ }^{23}$. Sn wire of diameter $2.0 \mathrm{~mm}$ and 99.9 mass $\%$ purity, which was used as the cathode, was placed at the center of the glass cell. Subsequently, the electrolysis was performed by applying a voltage of $250 \mathrm{~V}$ using a direct-current power-supply (ZX800H, Takasago). $300 \mathrm{ml}$ of $0.005 \mathrm{M} \mathrm{K}_{2} \mathrm{CO}_{3}$ solution was used as the 
electrolyte. Besides, the effect of surfactant (CTAB) concentration was analyzed by adding CTAB of concentration ranging from 0 to $200 \times 10^{-6} \mathrm{~g} \cdot \mathrm{ml}^{-1}$ to the electrolyte solution. Before electrolysis, the solution was heated over $60^{\circ} \mathrm{C}$. During electrolysis, the solution was stirred using a magnetic stirrer at a rate of $1000 \mathrm{rpm}$. Powder X-ray diffraction (XRD, Miniflex, Rigaku, $\mathrm{Cu}-\mathrm{K} \alpha$ ), scanning electron microscopy (SEM, JSM-7001FA, JEOL) and transmission electron microscopy (TEM, JEM-2010F, JEOL) were used to analyze the prepared samples. Sn-NP/graphite composites were prepared by adding graphite powder of diameter $15 \mu \mathrm{m}$ (Expanded Graphite EC1000, Ito Kokuen) to the Sn-NP-dispersed solution.

\subsection{Preparation of cell and electrochemical measurements}

The electrochemical characterizations were carried out in two-electrode

Swagelok-type cells ${ }^{24,25}$. The working electrode consisted of an active material, conductive carbon (acetylene black), and a polymer binder (polyvinyl alcohol) in the weight ratio of 75:15:10. The well-blended slurry was pasted onto a copper foil and dried at $60{ }^{\circ} \mathrm{C}$ for $12 \mathrm{~h}$ in vacuum. The dried electrode was punched into a disc of diameter $10 \mathrm{~mm}$ and pressed under a pressure of $20 \mathrm{MPa}$. A metallic lithium disc of diameter $10 \mathrm{~mm}$ was used as the counter and reference electrode. The cells were assembled in an Ar-filled glove box (UNICO), using a solution of $1 \mathrm{M} \mathrm{LiPF}_{6}$ dissolved 
in ethylene carbonate (EC)/dimethyl carbonate (DMC) $(1: 1 \mathrm{v} / \mathrm{v})$ as electrolyte and polypropylene membrane as a separator. The cells were galvanostatically cycled from 0.01 to $2.0 \mathrm{~V}$ versus $\mathrm{Li} / \mathrm{Li}^{+}$at $0.2 \mathrm{C}$ in the constant current mode using a battery tester (PFX2011, Kikusui). Cycling voltammograms (CV) were measured at a scanning rate of $0.1 \mathrm{mV} \cdot \mathrm{s}^{-1}$ using a potentiostat (PGSTAT $128 \mathrm{~N}$, Metrohm Autolab).

\section{Results and discussions}

\subsection{Effect of the CTAB concentration}

Figure 1 shows the XRD patterns of the different samples (Sn-NPs) prepared with various concentrations of CTAB. Figure 2 shows the corresponding microstructural analysis performed using SEM. In case of sample prepared without the addition of

CTAB (labeled as "CTAB-0" in Fig. 1), the XRD pattern revealed the formation of SnO plates containing $\mathrm{Sn}_{6} \mathrm{O}_{4}(\mathrm{OH})_{4}$ particles. The TEM observation of this sample, reported by us elsewhere ${ }^{21}$, indicated the formation of single-crystalline tetragonal $\mathrm{SnO}$ plates, with the plate faces on the (001) plane. In addition, the systematic characterization revealed that the $\mathrm{SnO}$ plates and $\mathrm{Sn}_{6} \mathrm{O}_{4}(\mathrm{OH})_{4}$ particles were precipitated from $\mathrm{Sn}(\mathrm{OH})_{3}{ }^{-}$ ions, as described by the following equations:

$$
\begin{aligned}
& 6 \mathrm{Sn}(\mathrm{OH})_{3}{ }^{-} \rightarrow \mathrm{Sn}_{6} \mathrm{O}_{4}(\mathrm{OH})_{4}+4 \mathrm{H}_{2} \mathrm{O}+6(\mathrm{OH})^{-} \\
& \mathrm{Sn}(\mathrm{OH})_{3}{ }^{-} \rightarrow \mathrm{SnO}+\mathrm{H}_{2} \mathrm{O}+(\mathrm{OH})^{-}
\end{aligned}
$$


In case of sample synthesized in the presence of 10 and $30 \times 10^{-6} \mathrm{~g} \cdot \mathrm{ml}^{-1}$ of CTAB, the size of the $\mathrm{SnO}$ plates was found to decrease, with the formation of a small amount of metallic Sn. On further increasing the CTAB concentration to $200 \times 10^{-6} \mathrm{~g} \cdot \mathrm{ml}^{-1}$, we could obtain $150 \mathrm{mg}$ of Sn nanoparticles (Sn-NPs) of diameter $<200 \mathrm{~nm}$, upon $7 \mathrm{~min}$ of electrolysis with average current of 0.43 A. Furthermore, the crystal structure of the prepared Sn-NPs was analyzed by using TEM to clarify the location of the oxide $\mathrm{SnO}_{2}$. Figure 3(a) shows the bright-field TEM image of the prepared Sn-NPs and Fig. 3(b) shows the selected area electron diffraction (SAED) pattern corresponding to the area (b), shown with a dotted line in Fig. 3 (a). From TEM images, the mean diameter of the Sn-NPs was $48 \mathrm{~nm}$. The SAED pattern confirmed the formation of single-crystalline tetragonal Sn-NPs. Besides, we could also observe the formation of multi-crystalline Sn particles and colloidal $\mathrm{SnO}_{2}$ particles of diameter of $<10 \mathrm{~nm}$. Figures 3(c) and (d) show the high-resolution TEM images taken from the area (c) and (d) shown with a solid line in Fig. 3(a). As evidenced from Fig. 3(d), an oxide layer was formed on the surface of $\mathrm{Sn}$ particles. These $\mathrm{SnO}_{2}$ phases were probably produced as a result of the high-temperature atmosphere surrounding the Sn electrode surface. After the experiments, the oxide phase might have been formed during the drying process. 
Fig. 4 shows the possible formation mechanism underlying the formation of Sn-NPs upon the addition of CTAB. The solution near the cathodic plasma is heated to the boiling point and a vapor was generated. When the sample was synthesized without $\mathrm{CTAB}$, the resulting sample was $\mathrm{SnO}$ plates, which was precipitated from $\mathrm{Sn}(\mathrm{OH})_{3}{ }^{-}$ ions formed from the oxidation and ionization of Sn-NPs. On the other hand, when the sample was synthesized with CTAB, Sn-NPs were formed in addition to SnO plates. This could be attributed as the effect of $\mathrm{CTAB}$, explained as follows. CTAB is a cationic surfactant, which ionizes completely in water to form $\mathrm{CTA}^{+}$. The $\mathrm{CTA}^{+}$formed in the aqueous solution might have probably attached to the surface of Sn-NPs, to stabilize the metallic particles. If the solution contains large quantities of CTAB sufficient to cover whole surface of Sn-NPs, the formation of $\mathrm{Sn}(\mathrm{OH})_{3}{ }^{-}$ions on the Sn-NPs surface is prevented. According to our experiments, $1 \mathrm{mg}$ of CTAB was needed to produce $1 \mathrm{~g}$ of Sn-NPs. In addition, the optimum temperature range was determined to be $70-84{ }^{\circ} \mathrm{C}$.

The surface area of particles and adsorption area of CTAB molecules were calculated for comparison. When all particles are spheres with $48 \mathrm{~nm}$ diameter, surface area of these particles can be calculated from amount of production and density of metallic Sn as shown in Table I. Actual surface area will be increased due to surface roughness of 
particles and existence of colloidal $\mathrm{SnO}_{2}$ nanoparticles shown in Fig.3 (c) with the particle size less than $10 \mathrm{~nm}$.

Table I surface area of particles calculated from the mean diameter, amount of production and density of metallic Sn.

\begin{tabular}{lr}
\hline Mean diameter & $48 \mathrm{~nm}$ \\
Production amount & $150 \mathrm{mg}$ \\
Density of metallic $\beta-\mathrm{Sn}$ & $7.365 \mathrm{~g} \cdot \mathrm{cm}^{-}$ \\
& 3 \\
Surface area of particles & $2.55 \mathrm{~m}^{2}$ \\
\hline
\end{tabular}

According to the literature ${ }^{25}$, the adsorption area of one CTAB molecule is $0.35 \mathrm{~nm}^{2}$. On the assumption of monomolecular adsorption of CTAB, the total absorption area of CTAB was estimated. Table II shows the adsorption area of CTAB molecules at each concentration. In the case of $200 \times 10^{-6} \mathrm{~g} \cdot \mathrm{ml}^{-1}$ of CTAB, the adsorption area was 34.68 $\mathrm{m}^{2}$ which is larger than the surface area of Sn-NPs.

Table II adsorption area of CTAB molecules at each concentration.

\begin{tabular}{rr}
\hline Concentration $\left(\mathrm{g} \cdot \mathrm{ml}^{-1}\right)$ & Adsorption area $\left(\mathrm{m}^{2}\right)$ \\
\hline $1 \times 10^{-6}$ & 0.17 \\
$10 \times 10^{-6}$ & 1.73 \\
$30 \times 10^{-6}$ & 5.20 \\
$200 \times 10^{-6}$ & 34.68 \\
\hline
\end{tabular}




\subsection{Electrochemical properties for Li-ion batteries}

The electrochemical properties of the $\mathrm{SnO}$ plate, prepared without the addition of

CTAB, were studied using constant current charge/discharge measurement. For that, the anode was formed by preparing a composite of $\mathrm{SnO}$ plates and graphite. During the first charge/discharge process, $\mathrm{Li}_{2} \mathrm{O}$ and metallic $\mathrm{Sn}$ were formed, according to the following equation (3).

$$
\mathrm{SnO}+2 \mathrm{Li} \rightarrow \mathrm{Sn}+\mathrm{Li}_{2} \mathrm{O}
$$

Figure 5 shows the cyclic performance of the $\mathrm{SnO}$ plates and $\mathrm{SnO}$ plate/graphite composite. In both the samples, the decrease in capacities was induced by large volume expansion during the lithium-ion insertion process, in which the SnO-plate was mechanically damaged, cracked, and pulverized. Inset of Fig. 5 is merely the corresponding SEM image of the sample. It was observed that the flat $\mathrm{SnO}$ plate was pulverized to particles after 20 cycles. These pulverized particles might have peeled from the electrode or lost the connection with copper collector, which lead to the observed decrease in capacity ${ }^{27}$.

Furthermore, the electrochemical properties of the synthesized Sn-NP/graphite composite (Sn-NPs 30\%) were evaluated. For comparison, the cyclic performances of 
pure graphite and pure Sn-NPs (Sn-NPs 100\%) were also recorded. Figure 6 shows the cyclic performance of the samples. In the case of Sn-NPs $100 \%$, the discharge capacity was found to decrease dramatically. The decrease in capacities was induced by large volume expansion during the lithium-ion insertion process. In contrast, it was found that the discharge capacity of Sn-NPs $30 \%$ was $414 \mathrm{mAh} \cdot \mathrm{g}^{-1}$ after 20 cycles owing to the buffer space provided by the graphite for volume expansion. In the first cycle, the columbic capacity was calculated to be $66 \%$, based on the discharge capacity of 653 $\mathrm{mAh} \cdot \mathrm{g}^{-1}$ and charge capacity of $433 \mathrm{mAh} \cdot \mathrm{g}^{-1}$. This is usually due to the irreversible reactions, such as the formation of a solid electrolyte interface (SEI) layer and the decomposition of solvent in the electrolyte ${ }^{13}$. Low columbic efficiency in the first cycle might have been caused by the formation of SEI layer owing to the high surface area of Sn-NPs.

Additionally, the irreversible reduction of $\mathrm{SnO}_{2}$ on the $\mathrm{Sn}-\mathrm{NP}$ surface to metallic $\mathrm{Sn}$ occurred by following equation (5).

$$
\mathrm{SnO}_{2}+4 \mathrm{Li} \rightarrow \mathrm{Sn}+2 \mathrm{Li}_{2} \mathrm{O}
$$

In the $2^{\text {nd }}$ cycle, the efficiency was increased to $93 \%$ and above $95 \%$ after 18 cycles. Compared to the theoretical capacity of $559 \mathrm{mAh} \cdot \mathrm{g}^{-1}$ in Sn-NPs $30 \%$, the discharge 
capacity after 20 cycles decreased to $414 \mathrm{mAh} \cdot \mathrm{g}^{-1}$, owing to the formation of $\mathrm{SnO}_{2}$ and weak bonding force between Sn-NPs and graphite. According to the SEM image shown in Fig.6, the Sn nanoparticles attached to the graphite surface. However, in this study, the Sn and graphite were just simply mixed together, and they may be lack of good adhesion or contact. The method for composite preparation requires further improvement in order to enhance the capacity and cyclic properties.

\section{Conclusions}

Sn-NPs were synthesized by a novel surfactant-assisted solution plasma technique.

The electrochemical performances of Sn-NPs and Sn-NP/graphite composites were analyzed. Based on the characterization of the prepared samples, the following conclusions were derived:

(1) Sn-NPs were synthesized in the presence of different concentrations of surfactant (CTAB). At a high concentration of $200 \times 10^{-6} \mathrm{~g} \cdot \mathrm{ml}^{-1}$ of CTAB, the yield of Sn-NPs was found to be $150 \mathrm{mg}$. SEM and TEM observations indicated that the diameter of prepared Sn-NPs was $<200 \mathrm{~nm}$, and the particle surface was partially oxidized.

(2) $\mathrm{SnO}$ plate was pulverized to particles after 20 cycles and the discharge capacity was decrease dramatically. 
(3) Electrochemical studies revealed that the discharge capacity of the sample Sn-NPs $30 \%$ was $414 \mathrm{mAh} \cdot \mathrm{g}^{-1}$ after 20 cycles.

We hope that these findings will lead to further developments in the use of solution plasma technique for the synthesis of electrode materials for batteries. The solution plasma technique can be extended for the synthesis of alloy nanoparticle systems, such as $\mathrm{Sn}_{\mathrm{x}} \mathrm{Sb}$, which might exhibit better cyclic stability owing to its low volume expansion during lithiation. 


\section{References}

[1] Y Idota, T Kubota, A Matsufuji, Y Maekawa and T Miyasaka, Tin-Based Amorphous Oxide: A High-Capacity Lithium-Ion-Storage Material, Science, 276 (1997) 1395-7.

[2] A Caballero, J Morales and L Sanchez, Tin Nanoparticles Formed in the Presence of Cellulose Fibers Exhibit Excellent Electrochemical Performance as Anode Materials in Lithium-Ion Batteries, Electrochemical and Solid-State Letters, 8 (2005) A464-A6.

[3] J M Tarascon and M Armand, Issues and challenges facing rechargeable lithium batteries, Nature, 414 (2001) 359.

[4] A R Kamali and D J Fray, Tin-based materials as advanced anode materials for lithium ion batteries: a review, Reviews on Advanced Materials Science, 27 (2011) 14-24.

[5] $\mathrm{M}$ Winter and $\mathrm{J} \mathrm{O}$ Besenhard, Electrochemical lithiation of tin and tin-based intermetallics and composites, Electrochimica Acta, 45 (1999) 31-50.

[6] M M Thackeray, J T Vaughey, C S Johnson, A J Kropf, R Benedek, L M L Fransson and K Edstrom, Structural considerations of intermetallic electrodes for lithium batteries, Journal of Power Sources, 113 (2003) 124-30.

[7] J He, H Zhao, J Wang, J Wang and J Chen, Hydrothermal synthesis and electrochemical properties of nano-sized Co-Sn alloy anodes for lithium ion batteries, Journal of Alloys and Compounds, 508 (2010) 629-35.

[8] G Wang, Y Q Ma, Z Y Liu and J N Wu, Novel highly porous Sn-C composite as high performance anode material for lithium-ion batteries, Electrochimica Acta, 65 (2012) 275-9.

[9] X Zhou, Y Zou and J Yang, Carbon supported tin-based nanocomposites as anodes for Li-ion batteries, Journal of Solid State Chemistry, 198 (2013) 231-7.

[10] Y Xu, Q Liu, Y Zhu, Y Liu, A Langrock, M R Zachariah and C Wang, Uniform Nano-Sn/C Composite Anodes for Lithium Ion Batteries, Nano Letters, 13 (2013) 470-4.

[11] M K Datta, R Epur, P Saha, K Kadakia, S K Park and P N Kumta, Tin and graphite based nanocomposites: Potential anode for sodium ion batteries, Journal of Power Sources, 225 (2013) 316-22.

[12] Y-J Kim, M-S Park, H-J Sohn and H Lee, Electrochemical behaviors of SnO and $\mathrm{Sn}$ anodes for lithium rechargeable batteries, Journal of Alloys and Compounds, 509 (2011) 4367-71. 
[13] J Y Lee, R Zhang and Z Liu, Dispersion of Sn and SnO on carbon anodes, Journal of Power Sources, 90 (2000) 70-5.

[14] L Balan, J Ghanbaja, P Willmann and D Billaud, Novel tin-graphite composites as negative electrodes of Li-ion batteries, Carbon, 43 (2005) 2311-6.

[15] D Billaud, L Balan, R Schneider and P Willmann, The influence of the synthesis conditions of graphite/tin nanoparticle materials on their electrode electrochemical performance in Li-ion battery anodes, Carbon, 44 (2006) 2508-15.

[16] Y Lee and Y-M Kang, Sn nanocrystal/carbon composites as high-capacity anode materials for lithium rechargeable batteries, Journal of Power Sources, 196 (2011) 10686-91.

[17] Z Chen, Y Cao, J Qian, X Ai and H Yang, Facile synthesis and stable lithium storage performances of Sn- sandwiched nanoparticles as a high capacity anode material for rechargeable Li batteries, Journal of Materials Chemistry, 20 (2010) 7266-71.

[18] M-Y Li, Y Wang, C-L Liu, C Zhang and W-S Dong, Synthesis of Carbon/Tin Composite Anode Materials for Lithium-Ion Batteries, Journal of the Electrochemical Society, 159 (2012) A91-A7.

[19] G Saito, S Hosokai, M Tsubota and T Akiyama, Nickel Nanoparticles Formation from Solution Plasma Using Edge-Shielded Electrode, Plasma Chemistry and Plasma Processing, 31 (2011) 719-28.

[20] Y Toriyabe, S Watanabe, S Yatsu, T Shibayama and T Mizuno, Controlled formation of metallic nanoballs during plasma electrolysis, Applied Physics Letters, 91 (2007) 041501-3.

[21] X Hu, S-P Cho, O Takai and N Saito, Rapid Synthesis and Structural Characterization of Well-Defined Gold Clusters by Solution Plasma Sputtering, Crystal Growth \& Design, 12 (2011) 119-23.

[22] A A Ashkarran, A Iraji zad, S M Mahdavi and M M Ahadian, ZnO nanoparticles prepared by electrical arc discharge method in water, Materials Chemistry and Physics, 118 (2009) 6-8.

[23] G Saito, S Hosokai, M Tsubota and T Akiyama, Influence of Solution Temperature and Surfactants on Morphologies of Tin Oxide Produced Using a Solution Plasma Technique, Crystal Growth \& Design, 12 (2012) 2455-9.

[24] C Zhu, G Saito and T Akiyama, A new CaCO3-template method to synthesize nanoporous manganese oxide hollow structures and their transformation to high-performance LiMn2O4 cathodes for lithium-ion batteries, Journal of 
Materials Chemistry A, 1 (2013) 7077-82.

[25] C. Zhu, A. Nobuta, G. Saito, I. Nakatsugawa and T. Akiyama, Solution combustion synthesis of LiMn2O4 fine powders for lithium ion batteries, Advanced Powder Technology (2013) in press.

[26] JIS K6430 : 2008, Appendix G, page 23.

[27] H Uchiyama, E Hosono, I Honma, H Zhou and H Imai, A nanoscale meshed electrode of single-crystalline $\mathrm{SnO}$ for lithium-ion rechargeable batteries, Electrochemistry Communications, 10 (2008) 52-5. 
Figure captions

Fig. 1. XRD patterns of the samples synthesized with different concentrations of CTAB (0 to $200 \times 10-6 \mathrm{~g} \cdot \mathrm{ml}-1)$.

Fig. 2. SEM images of samples synthesized with different concentrations of CTAB.

Fig. 3. TEM images of the sample obtained by the addition of $200 \times 10-6 \mathrm{~g} \bullet \mathrm{ml}-1$ of CTAB.

Fig. 4. Mechanism proposed for the formation of Sn nanoparticles in the presence of CTAB.

Fig. 5. Discharge capacity of the $\mathrm{SnO}$ products in the range of $0.01-2 \mathrm{~V}$ at a cycling rate of $0.2 \mathrm{C}$ with the binder of PVDF. The product of $\mathrm{SnO}$-plate $30 \%$ is a mixture of $\mathrm{SnO}$ plate and graphite. Inset images show the SEM images of SnO plates of (a) as-prepared electrode and (b) after 20 cycles.

Fig. 6. Discharge capacity of the Sn-NPs $30 \%$, Sn-NPs $100 \%$ and graphite composite with the binder of PVA in the range of $0.01-2 \mathrm{~V}$ at a cycling rate of $0.2 \mathrm{C}$. Inset images show the SEM images of the composite. 
Figure 1

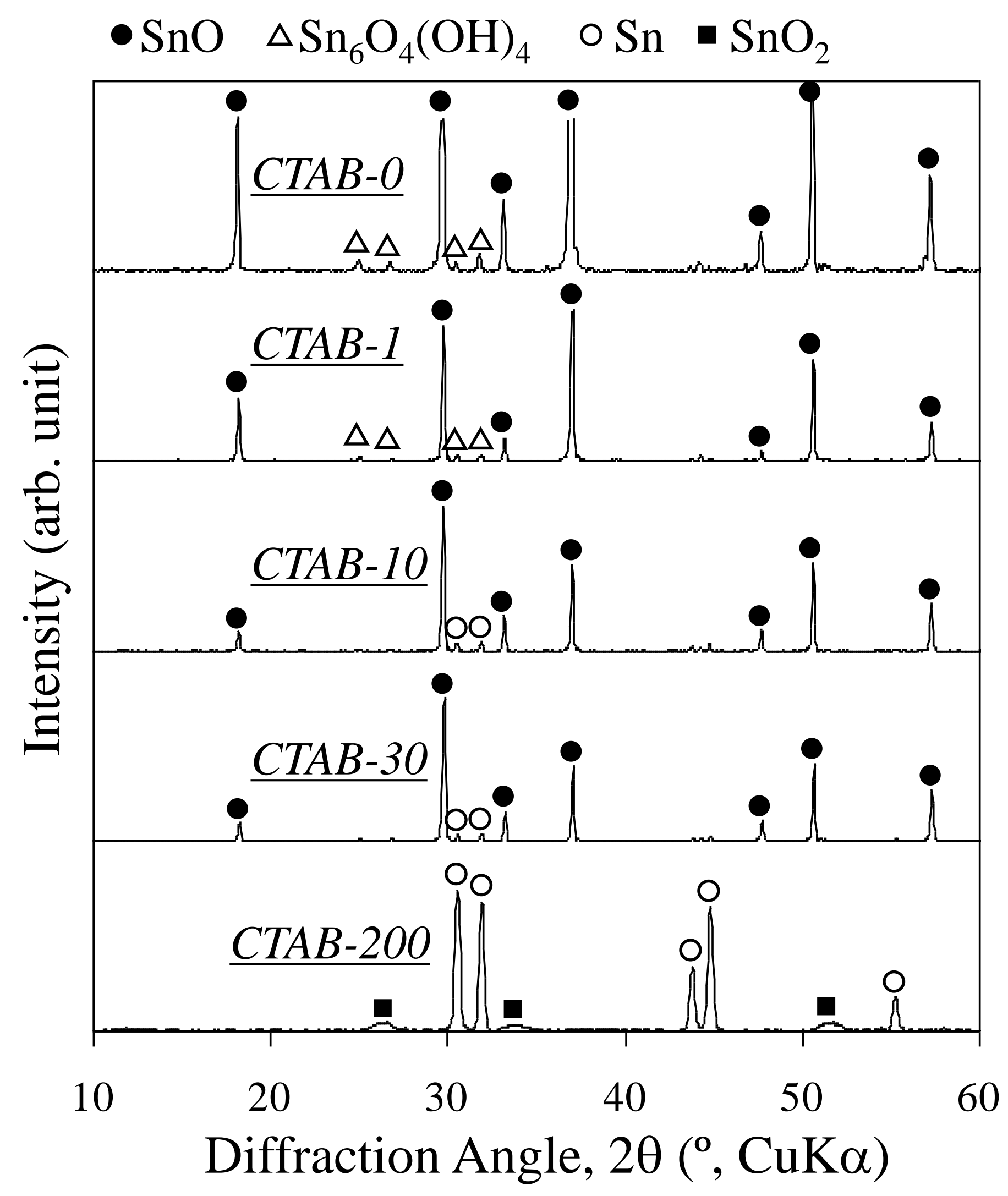


Figure 2
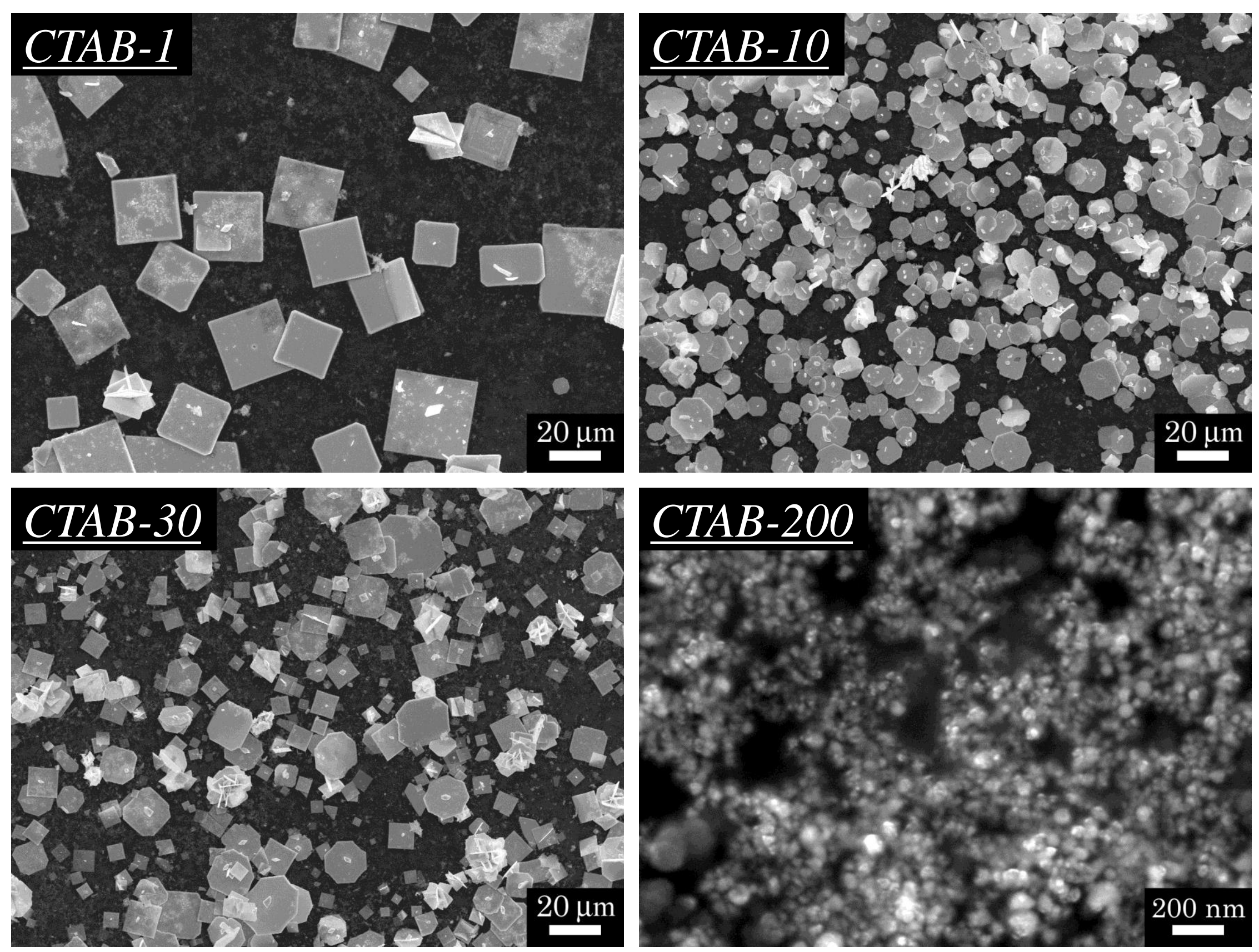

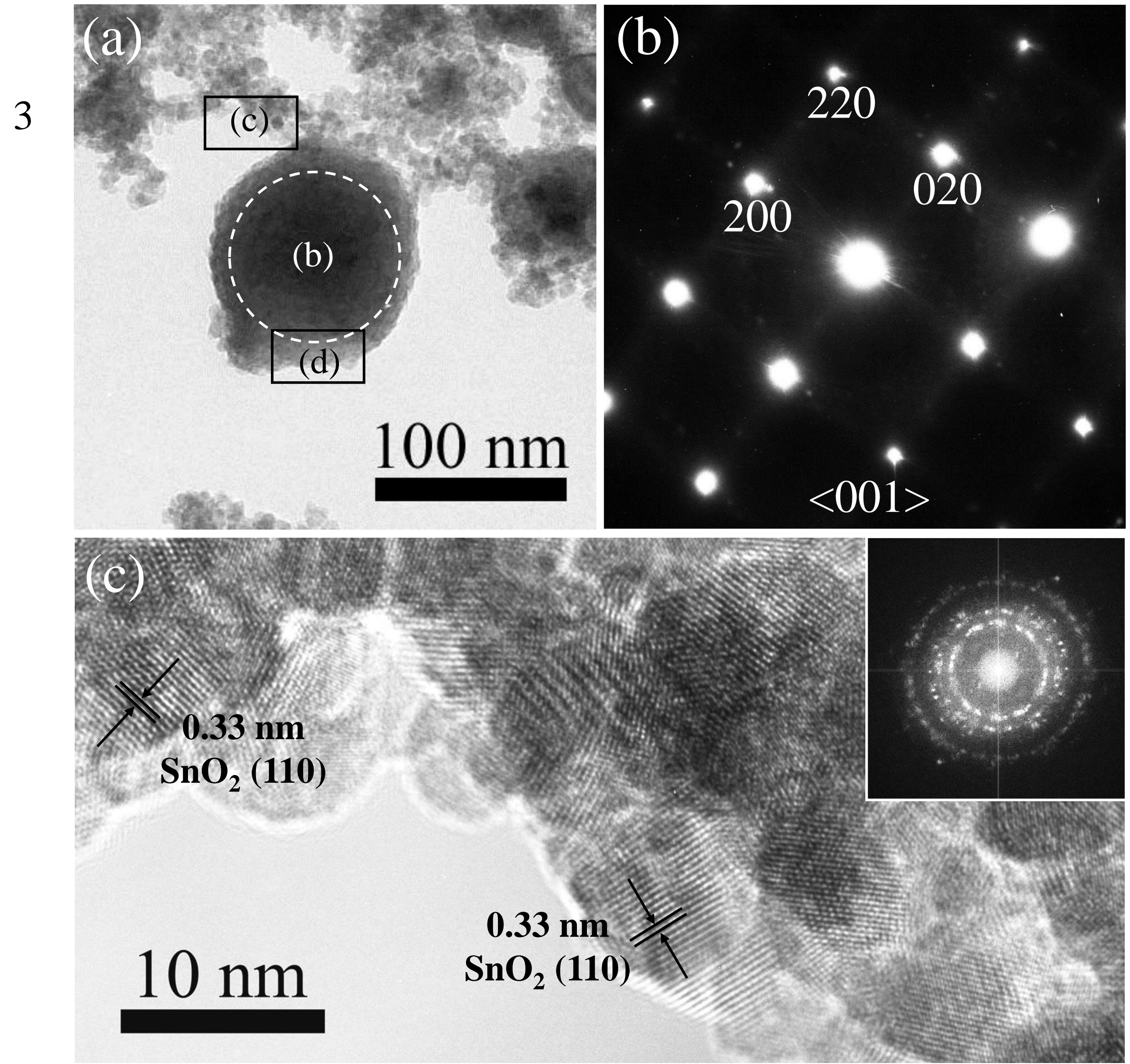

(d)

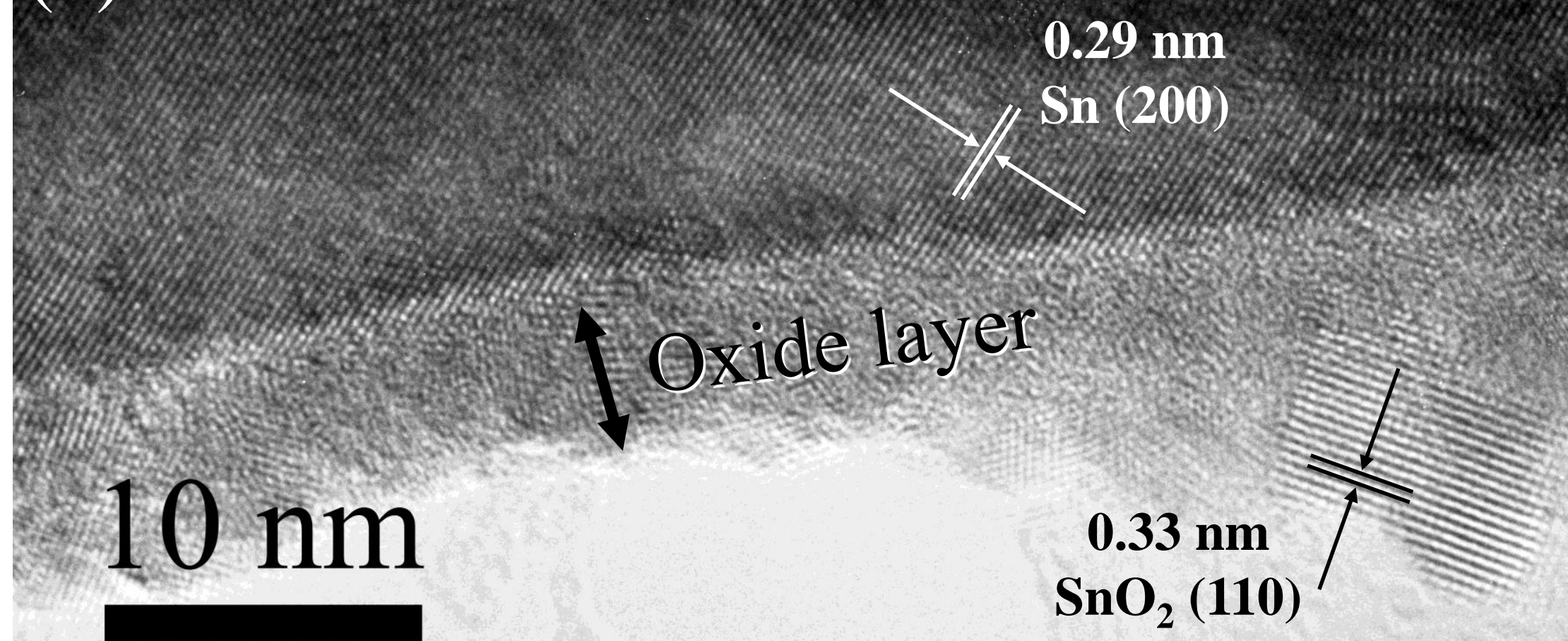


Figure 4

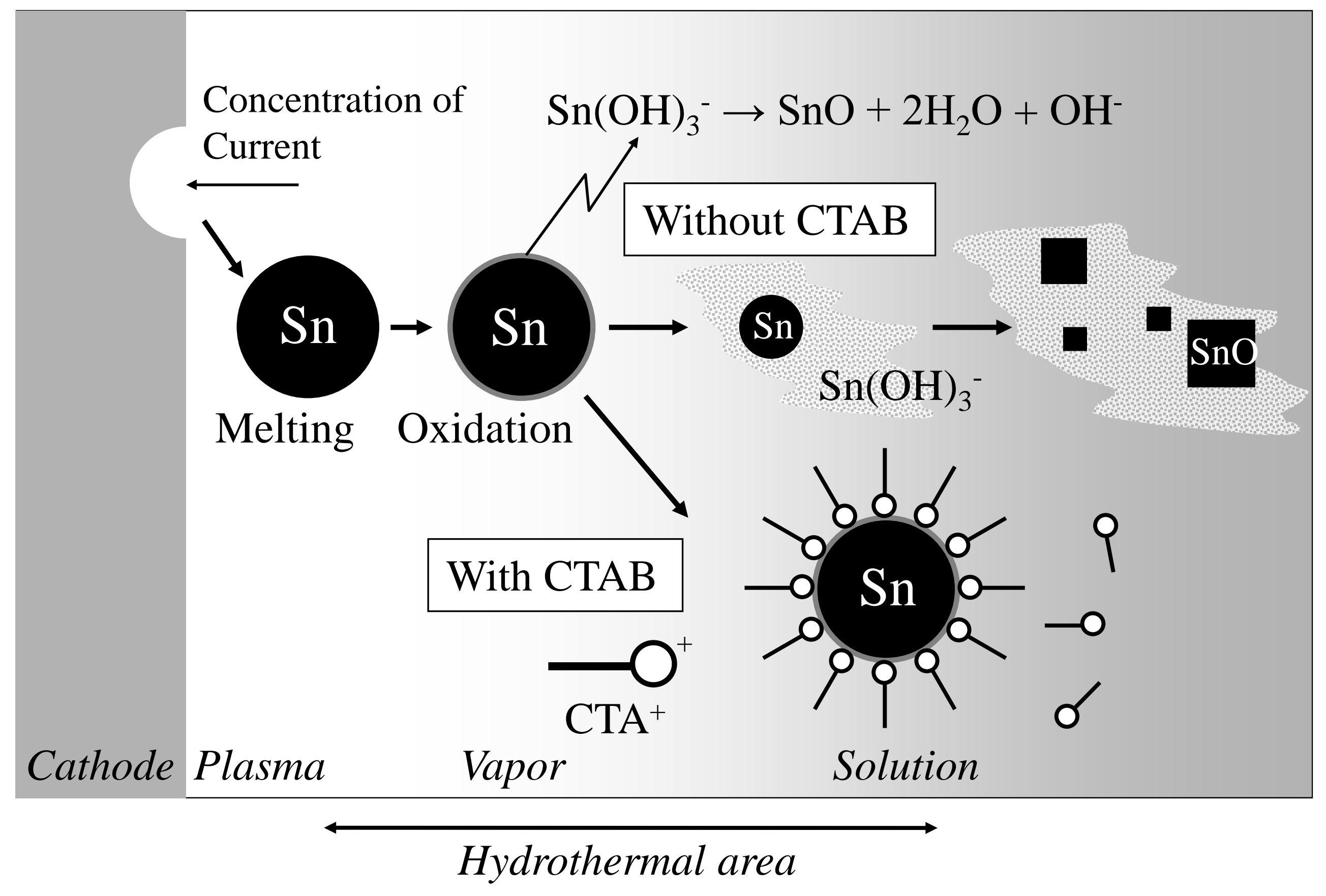


Figure 5

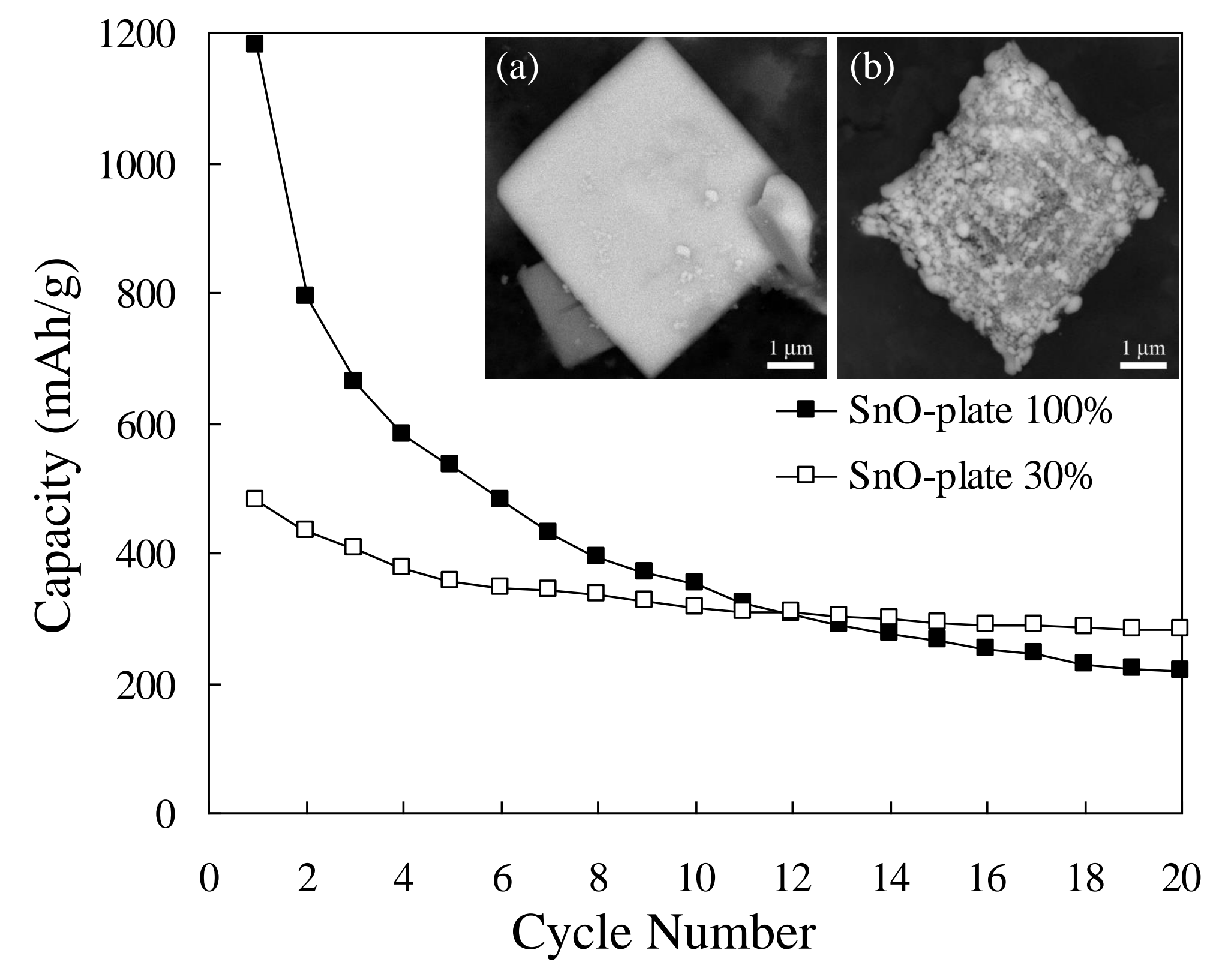


Figure 6

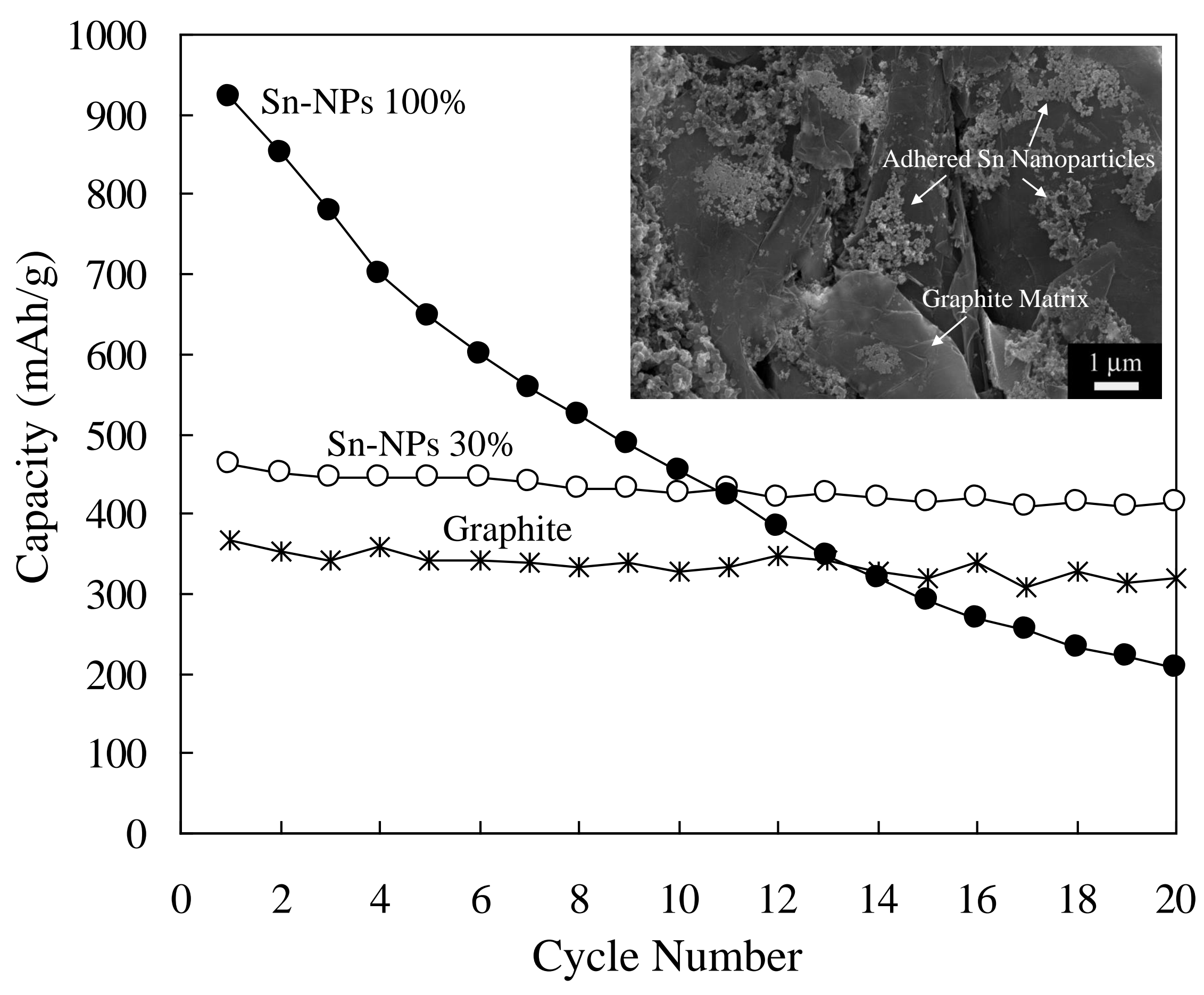

